\title{
Impact of malocclusion severity on oral health-related quality of life in an Iranian young adult population
}

\author{
Kazem Dalaie ${ }^{1}$, Mohammad Behnaz ${ }^{2}$, Zahra Khodabakhshi ${ }^{3}$, Sepanta Hosseinpour ${ }^{4}$
}

Correspondence: Dr. Sepanta Hosseinpour

Email: sp.hosseinpour@gmail.com

\author{
'Dental Research Center, Research Institute of Dental \\ Research, School of Dentistry, Shahid Beheshti \\ University of Medical Sciences, Tehran, Iran, \\ ${ }^{2}$ Department of Orthodontics, School of Dentistry, \\ Shahid Beheshti University of Medical Sciences, \\ Tehran, Iran, \\ ${ }^{3}$ Dentist, Tehran, Iran, \\ ${ }^{4}$ School of Advanced Technologies in Medicine, Shahid \\ Beheshti University of Medical Sciences, Tehran, Iran
}

\section{ABSTRACT}

Objective: This study aimed to assess the relationship between malocclusion severity and oral health-related quality of life (QoL) of 18 to 25-year-old Iranians who sought orthodontic treatment. Materials and Methods: A total of 126 patients between 18 and 25 years attending some private orthodontic clinics answered the oral health impact profile-14 (OHIP-14) and a demographic questionnaire. Two calibrated orthodontists recorded the Index of Orthodontic Treatment Need-Dental Health Component (IOTN-DHC) determining the severity of malocclusion (Kappa $=0.8$ ). The IOTN-Aesthetic Component $($ IOTN-AC) was reported by patients for assessing the perception of their esthetic severity of malocclusion. Logistic regression analysis was used. Level of significance was set at $\alpha=0.05$. Results: The mean score of OHIP-14 was $20.87 \pm 8.6$. The frequency of patients with no/slight, borderline, and definite need for orthodontic treatment was determined as $13.4 \%, 23.8 \%$, and $62.7 \%$, respectively, by IOTN-DHC. There were significant correlations between borderline or definite need treatment and OHIP-14 overall score $(P<0.05)$. Patients with borderline and definite need for orthodontic treatment had 5 and 21 times lower QoL, respectively, than those with a slight need for orthodontic treatment. Based on IOTN-AC, 50.8\% of the patients mentioned slight or no need based on IOTN-AC. No significant association was noted between IOTN-AC and OHIP-14 overall scores. Conclusions: The results showed negative impact of malocclusion severity on the QoL. This study highlighted the importance of individual assessment of orthodontic patients.

Key words: Index of Orthodontic Treatment Need, malocclusion, Oral Health Impact Profile-14, oral health-related quality of life

\section{INTRODUCTION}

The relationship between health status and the quality of life (QoL) has been well documented. ${ }^{[1]}$ The Oral Health-Related Quality of Life (OHRQoL) is an important parameter for patients' assessment

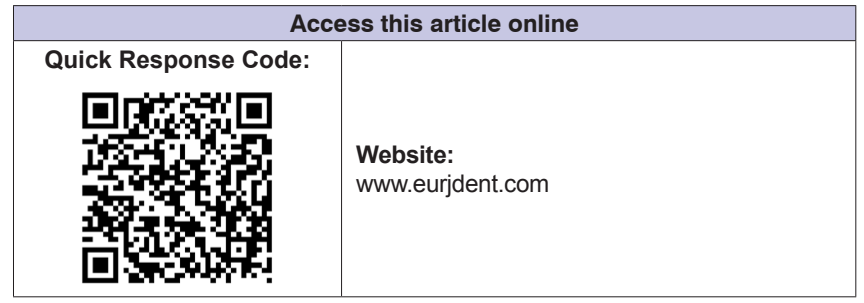

in domains related to physical and mental health including malocclusion. ${ }^{[2]}$ In other words, OHRQoL refers to the impact of oral conditions on daily activities, health, and the QoL. ${ }^{[3]}$ Therefore, oral cavity

This is an open access article distributed under the terms of the Creative Commons Attribution-NonCommercial-ShareAlike 3.0 License, which allows others to remix, tweak, and build upon the work non-commercially, as long as the author is credited and the new creations are licensed under the identical terms.

For reprints contact: reprints@medknow.com

How to cite this article: Dalaie $\mathrm{K}$, Behnaz M, Khodabakhshi Z, Hosseinpour S. Impact of malocclusion severity on oral health-related quality of life in an Iranian young adult population. Eur $\mathrm{J}$ Dent 2018;12:129-35.

DOI: 10.4103/ejd.ejd_61_17 
is not considered an independent landmark and more emphasis has been placed on the impact of oral health on general health, well-being, and QoL. ${ }^{[4]}$ High prevalence of malocclusion in different communities, ${ }^{[5]}$ especially in the Iranian population, ${ }^{[6]}$ its physical, economic, social, and psychological consequences, and the effect of malocclusion on the QoL, function, appearance, and interpersonal relationship, ${ }^{[7]}$ all point to the importance of evaluating the effect of malocclusion severity on different aspects of life based on personal opinions of individuals. ${ }^{[5]}$

Based on all the above findings, in the assessment of orthodontic treatment need, QoL-related factors from the patients' perspectives such as occlusal parameters based on the perspectives of dentists must also be considered because the social and psychological factors are the main motives for patients seeking orthodontic treatment. Occlusal factors are not the only determinants of the need for orthodontic treatment or the severity of malocclusion. ${ }^{[8,9]}$ The relationship of malocclusion and the OHRQoL in different communities due to its unpredictability necessitates separate evaluations within various communities. ${ }^{[10]}$ Several parameters are used for the assessment of malocclusion. The Index of Orthodontic Treatment Need (IOTN) is a scoring system for malocclusion which has been internationally confirmed in terms of validity, reliability, and simple application.

The Oral Health Impact Profile (OHIP) questionnaire has been extensively used to assess the OHRQoL. The original form of this questionnaire has 49 items; the truncated form has 14 items. ${ }^{[11]}$ Several studies have demonstrated a correlation between OHRQoL and malocclusion, ${ }^{[4,10,12,13]}$ while some others did not find any correlation. ${ }^{[11,14,15]}$

The reliability of the translated versions of OHIP-14 to many languages ${ }^{[16-18]}$ has been approved for the 18-78 years olds. Previous studies confirmed validity and reliability of the Persian translation of this questionnaire. ${ }^{[19,20]}$

The correlation between the malocclusion severity and the concept of QoL needs to be further scrutinized. ${ }^{[8,11]}$ Orthodontic treatment is an expensive treatment modality for patients. Thus, it is important to find out whether the severity of malocclusion or the need for orthodontic treatment decreases the QoL of patients residing in Iran. In addition, assessment of the orthodontic treatment need is necessary for health plans. ${ }^{[8,21]}$ The current study sought to evaluate the relationship of the severity of malocclusion and OHRQoL of 18-25-year-old Iranians requiring orthodontic treatment.

\section{MATERIALS AND METHODS}

\section{Study population and data collection}

In this descriptive, cross-sectional study, participants were selected among those presenting to several private offices in Tehran using convenience sampling. The selected patients had not yet started orthodontic treatment (population size $=173$ ). The inclusion criteria were willingness for participation in the study, no history of orthodontic treatment, Iranian nationality, systemic healthy individuals, lack of craniofacial deformities such as cleft lip or palate, untreated caries, periodontal health and the Community Periodontal Index of 2 or lower, ${ }^{[22]}$ no history of tooth extraction, and extensive restorations or full crowns on molar teeth (due to their confounding effect on the QoL). The evaluated population was in the age range of $18-25$ years due to accessibility and existence of a proper self-esteem. After all, 126 including 99 females and 27 males participated in our study (response rate of $72.8 \%$ ). The study protocol was approved by the Committee of Medical Ethics of Shahid Beheshti University of Medical Sciences, School of dentistry. Patients were briefed about the method of conduction of the study and were ensured about the confidentiality of their information. Only patients who signed a written informed consent form were enrolled.

\section{Oral Health Impact Profile}

Data were collected using the Farsi version of OHIP-14 questionnaire. ${ }^{[2]}$ This questionnaire encompasses seven domains in which functional limitation, physical pain, psychological discomfort, physical disability, social disability, and handicap are evaluated. Each domain consists of two items. Each of the 14 items contained in the instrument can be scored with the scale of $0-5$. The score 0 refers to good QoL and 5 refers to worst. Hence, the total score ranges from 0 to $70 . \cdot^{[11,23]}$

The IOTN-Aesthetic Component (IOTN-AC) was used to assess the opinion of patients about the esthetic appearance of their teeth and their perceived orthodontic treatment need. The IOTN-AC included ten photographs showing different levels of dental attractiveness and esthetics. Level 1 shows the most attractive dental occlusion, while level 10 shows the least attractive dental occlusion. Levels 1-4 indicate slight or no need for treatment, levels 5-7 indicate 
moderate or borderline need, and levels 8-10 indicate definite need for treatment. ${ }^{[8,24]}$

\section{Oral assessments}

In order to determine the severity of malocclusion, IOTN-Dental Health Component (IOTN-DHC) was used blindly by two calibrated experienced orthodontists (faculty members of Shahid Beheshti University of Medical Sciences, School of Dentistry) twice with a 2-week interval. Using panoramic radiographs and lateral cephalograms and clinical evaluations, occlusal characteristics of patients were graded as follows: (5) very severe need for treatment, (4) severe need for treatment, (3) moderate need for treatment, (2) slight need for treatment, and (1) no need for treatment. ${ }^{[8,4]}$ A few complex cases were recalled for chair side examination (under unit light with a dental mirror and a Williams probe to determine the overjet and overbite) to ensure the accuracy of grading of IOTN-DHC. It should be noted that the intra- and inter-calibration coefficients were also calculated and found to be very good and good, respectively (kappa $=0.83$ and $\mathrm{kappa}=0.80$, respectively).

\section{Statistical analysis}

Data were analyzed using SPSS version 13 (Microsoft, Chicago, IL, USA). Level of significance was set at $a=0.05$. To assess the correlation of malocclusion severity and OHRQoL, logistic regression analysis was used. To assess the correlation of the severity of malocclusion with each of the QoL domains, ordinal logistic regression analysis was used.

\section{RESULTS}

\section{Oral health-related quality of life}

A total of 126 patients between 18 and 25 years (21.4\% males and $78.6 \%$ females with a mean age of $22.1 \pm 2.7$ years) participated in this study and filled out the questionnaires. The frequency of patients with no/slight, borderline, and definite need for orthodontic treatment was $13.4 \%, 23.8 \%$, and $62.7 \%$, respectively. In comparison between severity of malocclusion and OHRQoL, there were significant correlations between borderline or definite need treatment and OHIP-14 overall score $(P<0.05)$. By dichotomizing the QoL variable for assessment of its correlation with the severity of malocclusion and accounting for the effect of confounding variables such as age and sex using logistic regression analysis, it was found that by an increase in the severity of malocclusion, the QoL decreased by 5 and 21 times in the group with no/ slight need for treatment and the group with borderline and severe need for treatment, respectively, which was statistically significant [Table 1]. In the full model, after including other confounders such as level of education and occupation (in addition to age and sex), no change occurred in the power of correlation and level of significance of the association between the severity of malocclusion and the QoL [Table 2]. Table 3 represents correlation of the severity of malocclusion with daily activity of OHRQoL defined in OHIP-14 questionnaire. Table 4 reveals descriptive data of obtained IOTN-AC. However, in the assessment of intra-observer agreement, IOTN-AC and IOTN-DHC had a very weak correlation (weighted kappa $=0.15$ ). In addition, there is no relation between OHIP-14 overall score and IOTN-AC in each individual $(P=0.078)$.

\section{DISCUSSION}

Our results showed a significant association between malocclusion severity and OHRQoL. Based on the logistic regression results, the increase in malocclusion severity had a negative impact on the QoL by 5 and 21 times. The likelihood of reduction in the QoL was five times higher in those with borderline need for treatment (moderate severity of malocclusion) compared to those with no/slight need for treatment (less severe malocclusion). Furthermore, the likelihood of reduction in the QoL of patients with severe malocclusion and definite orthodontic treatment need was 21 times higher than that of patients with no/slight need for treatment and mild malocclusion $(\mathrm{OR}=5.1$ and 21.6, $P=0.04$ and 0.001, respectively).

The adverse effect of malocclusion severity on the QoL was also reported by Masood et al. Hassan and Amin who assessed the correlation of malocclusion severity and QoL using OHIP-14..$^{[4,10]}$ In addition, Heravi et al. and Bernabé et al. reported negative impact of malocclusion on OHRQoL via CPQ and OIDP. ${ }^{[12,25]}$ However, assessment of the QoL of patients

\begin{tabular}{lcccc}
$\begin{array}{l}\text { Table 1: Correlation of the severity of malocclusion } \\
\text { and the OHRQoL }\end{array}$ & P & OR & \multicolumn{2}{c}{$\mathbf{9 5 . 0 \%}$ CI for OR } \\
\cline { 2 - 5 } & & & Lower & Upper \\
\hline No/Little Treatment & 0.002 & & & \\
Borderline treatment & 0.04 & 5.1 & 1.06 & 24.6 \\
Need Treatment & 0.001 & 21.6 & 3.8 & 122.3 \\
Age & 0.41 & 1.1 & 0.8 & 1.3 \\
Male/Female & 0.73 & 1.3 & 0.2 & 7.7 \\
Constant & 0.55 & 0.2 & & \\
\hline
\end{tabular}




\begin{tabular}{|c|c|c|c|}
\hline \multirow[t]{2}{*}{ Gender } & \multicolumn{2}{|c|}{$\begin{array}{l}\text { Oral health related } \\
\text { quality of life }\end{array}$} & \multirow[t]{2}{*}{ Total } \\
\hline & No impact & Impact & \\
\hline \multicolumn{4}{|l|}{ Female } \\
\hline Count & 9 & 90 & 99 \\
\hline$\%$ within gender & $9.1 \%$ & $90.9 \%$ & $100.0 \%$ \\
\hline $\begin{array}{l}\% \text { within oral health } \\
\text { related quality of Life }\end{array}$ & $81.8 \%$ & $78.3 \%$ & $78.6 \%$ \\
\hline$\%$ of Total & $7.1 \%$ & $71.4 \%$ & $78.6 \%$ \\
\hline Male & 2 & 25 & 27 \\
\hline \multicolumn{4}{|l|}{ Count } \\
\hline$\%$ within gender & $7.4 \%$ & $92.6 \%$ & $100.0 \%$ \\
\hline $\begin{array}{l}\% \text { within oral health } \\
\text { related quality of life }\end{array}$ & $18.2 \%$ & $21.7 \%$ & $21.4 \%$ \\
\hline$\%$ of Total & $1.6 \%$ & $19.8 \%$ & $21.4 \%$ \\
\hline \multicolumn{4}{|l|}{ Total } \\
\hline Count & 11 & 115 & 126 \\
\hline$\%$ within gender* & $8.7 \%$ & $91.3 \%$ & $100.0 \%$ \\
\hline $\begin{array}{l}\% \text { within oral health } \\
\text { related quality of life }\end{array}$ & $100.0 \%$ & $100.0 \%$ & $100.0 \%$ \\
\hline$\%$ of Total & $8.7 \%$ & $91.3 \%$ & $100.0 \%$ \\
\hline
\end{tabular}

in the Orthodontics and Pedodontics Departments of Washington and Seattle Universities by Taylor et al. showed a poor correlation between malocclusion and OHRQoL. ${ }^{[14]}$ They used Index of Complexity, Outcome and Need for determination of the severity of malocclusion in 11-14 year olds and reported that malocclusion and even orthodontic treatment did not seem to affect the OHRQoL. ${ }^{[14]}$ Several explanations may be available for these results:

1. Use of different tools for measurement of OHRQoL

2. A wide range of differences might be related to differences in age groups or wide range of ages. It seems that each age group has a different perception of facial esthetics (especially oral and dental esthetics) and the QoL. It seems that children, adolescents, and the youth have different perceptions of these factors

3. Culture, beliefs, and social norms are variable in different countries and result in different expectations and perception of individuals of malocclusion and esthetics and their effects on the QoL. ${ }^{[12]}$

The results of Chi-square test showed no significant association between gender and OHRQoL, which is in line with the results of logistic regression. In this regard, Hassan and Amin and Masood et al. reported the same results. ${ }^{[4,10]}$ de Oliveira and Sheiham reported that oral health-related domains were affected by malocclusion 1.22 times more in females than in males. ${ }^{[26]}$ In a study by Heravi et al., females had higher frequency of seeking orthodontic treatment than males during the study period. In addition, females were more interested in seeking orthodontic treatments, which may be due to social acceptability and importance of esthetics. Moreover, it seems that parents are more interested in seeking orthodontic treatment for their female children than male children. Full-model logistic regression showed that inclusion of confounders such as level of education of patients and their parents and occupation, age, and sex caused no significant change in the association of malocclusion severity and QoL. The correlation of level of education and OHRQoL was significant. ${ }^{[12]}$ Masood et al. also stated that with regard to some functional domains of OHIP-14, patients with academic education reported higher frequency of impaired daily functions. ${ }^{[10]}$ Based on the results of the current study, gender significantly affected daily functions and the frequency of female patients reporting impaired daily functioning due to severity of malocclusion was higher than that of male patients. ${ }^{[10]}$ Oliveira and Sheiham reported that malocclusion in women significantly affected their daily functioning by 1.5 times more than men. ${ }^{[26]}$ However, Hassan and Amin represented that daily functioning was not correlated with gender of patients. ${ }^{[4]}$

The results showed that by one unit increase in the severity of malocclusion, the frequency of problems pronouncing words in males and females increased by 0.7 units. In other words, increased severity of malocclusion negatively affected the pronunciation of patients $(\mathrm{OR}=0.737, P=0.003)$. Lee et al. also demonstrated a strong association between orthodontic treatment need and pronunciation of words. ${ }^{[27]}$ These results are not in line with the results of a study by Hassan and Amin in Saudi Arabia. ${ }^{[4]}$ In both males and females, the correlation of malocclusion severity and pain in the mouth was weakly significant. By one unit increase in malocclusion severity, the frequency of pain in the mouth increased by 0.4 units $(\mathrm{OR}=0.489$, $P=0.038)$. This is in accordance with the results of previous studies reporting that malocclusion can directly and indirectly cause pain. Wright and North mentioned indirect pain due to temporomandibular joint problems when eating. ${ }^{[28]}$ Koroluk et al. reported direct pain due to trauma to proclined maxillary incisors. ${ }^{[29]}$ Shulman and Peterson stated that retroclined position of maxillary incisors could cause direct trauma to the labial gingiva and pain. ${ }^{[30]}$

Difficult eating, unsatisfactory diet, and interrupting meals were significantly correlated with malocclusion 
Dalaie, et al.: Malocclusion and oral health-related quality of life

\begin{tabular}{|c|c|c|c|c|c|c|c|c|}
\hline \multirow[t]{2}{*}{ OHIP-14 Daily activity } & \multicolumn{2}{|c|}{ No or little treatment } & \multicolumn{2}{|c|}{ Borderline treatment need } & \multicolumn{2}{|c|}{ Treatment need } & \multicolumn{2}{|c|}{$X^{2 *} P$} \\
\hline & Female 15 & Male 11 & Female 23 & Male 30 & Female 26 & Male 23 & Female & Male \\
\hline \multicolumn{9}{|c|}{ 1. Had problem pronouncing words } \\
\hline No impact: $n(\%)$ & $13(87)$ & $10(91)$ & $14(61)$ & $24(80)$ & $13(50)$ & $12(52)$ & 5.4 & 7.3 \\
\hline Impact: $n(\%)$ & $2(13)$ & $1(9)$ & $9(39)$ & $6(20)$ & $13(50)$ & 11() & 0.06 & $0.025^{*}$ \\
\hline \multicolumn{9}{|l|}{ 2. Had problem in tasting } \\
\hline No impact: $n(\%)$ & $10(67)$ & $9(82)$ & $2(9)$ & $22(73)$ & $18(70)$ & $3(13)$ & 5.4 & 5.2 \\
\hline Impact: $n(\%)$ & $5(33)$ & $2(18)$ & $21(91)$ & $8(26)$ & $8(30)$ & $20(87)$ & 0.08 & 0.07 \\
\hline \multicolumn{9}{|c|}{ 3. Had paiful aching in mouth } \\
\hline No impact: $n(\%)$ & $14(93)$ & $11(100)$ & $18(78)$ & $26(87)$ & $19(73)$ & $17(74)$ & 2.4 & 4.06 \\
\hline Impact: $n(\%)$ & $1(7)$ & $0(0)$ & $5(22)$ & $4(13)$ & $7(26)$ & $6(26)$ & 0.293 & 0.131 \\
\hline \multicolumn{9}{|c|}{ 4. Uncomfortable to eat food } \\
\hline No impact: $n(\%)$ & $11(73)$ & $11(100)$ & $19(83)$ & $28(93)$ & $13(50)$ & $16(70)$ & 6.2 & 8.2 \\
\hline Impact: $n(\%)$ & $4(27)$ & $0(0)$ & $4(17)$ & $2(7)$ & $13(50)$ & $7(30)$ & $0.045^{*}$ & $0.016^{*}$ \\
\hline \multicolumn{9}{|c|}{ 5. Have been self-conscious } \\
\hline No impact: $n(\%)$ & $2(13)$ & $6(55)$ & $2(9)$ & $2(7)$ & $0(0)$ & $0(0)$ & 3.2 & 21.9 \\
\hline Impact: $n(\%)$ & $13(87)$ & $5(45)$ & $21(91)$ & $28(93)$ & $26(100)$ & $23(100)$ & 0.197 & $0.001^{*}$ \\
\hline \multicolumn{9}{|l|}{ 6. Felt tense } \\
\hline No impact: $n(\%)$ & $10(67)$ & $9(82)$ & $16(70)$ & $23(77)$ & $7(27)$ & $13(57)$ & 10.6 & 3.3 \\
\hline Impact: $n(\%)$ & $5(33)$ & $2(18)$ & $7(30)$ & $7(23)$ & $19(73)$ & $10(43)$ & $0.005^{*}$ & 0.185 \\
\hline \multicolumn{9}{|c|}{ 7. Had an unsatisfactory diet } \\
\hline No impact: $n(\%)$ & $12(80)$ & $10(91)$ & $20(87)$ & $27(90)$ & $18(70)$ & $18(78)$ & 2.2 & 1.7 \\
\hline Impact: $n(\%)$ & $3(20)$ & $1(9)$ & $3(13)$ & $3(10)$ & $8(30)$ & $5(22)$ & 0.319 & 0.416 \\
\hline \multicolumn{9}{|l|}{ 8. Had to interrupt meal } \\
\hline No impact: $n(\%)$ & $14(93)$ & $11(100)$ & $23(100)$ & $29(96)$ & $21(81)$ & $22(96)$ & 5.4 & 0.47 \\
\hline Impact: $n(\%)$ & $1(7)$ & $0(0)$ & $0(0)$ & $1(4)$ & $5(19)$ & $1(4)$ & 0.065 & 0.789 \\
\hline \multicolumn{9}{|l|}{ 9.Found it difficult to relax } \\
\hline No impact: $n(\%)$ & $10(67)$ & $10(91)$ & $10(43)$ & $22(73)$ & $2(8)$ & $13(57)$ & 15.9 & 4.4 \\
\hline Impact: $n(\%)$ & $5(33)$ & $1(9)$ & $13(57)$ & $8(26)$ & $24(92)$ & $10(43)$ & $0.001^{*}$ & 0.107 \\
\hline \multicolumn{9}{|c|}{ 10. Have been a bit embarrassed } \\
\hline No impact: $n(\%)$ & $5(33)$ & $9(82)$ & $5(22)$ & $12(40)$ & $1(4)$ & $3(13)$ & 6.3 & 15.1 \\
\hline Impact: $n(\%)$ & $10(67)$ & $2(18)$ & $18(78)$ & $18(60)$ & $25(96)$ & $20(87)$ & $0.042^{*}$ & $0.001^{*}$ \\
\hline \multicolumn{9}{|c|}{ 11. Have been irritable with people } \\
\hline No impact: $n(\%)$ & $12(80)$ & $11(100)$ & $22(95)$ & $29(97)$ & $8(31)$ & $14(61)$ & 24.5 & 15.1 \\
\hline Impact: $n(\%)$ & $3(20)$ & $0(0)$ & $1(5)$ & $1(3)$ & $18(69)$ & $9(39)$ & $0.001^{*}$ & $0.001^{*}$ \\
\hline \multicolumn{9}{|c|}{ 12. Had difficulty doing usual jobs } \\
\hline No impact: $n(\%)$ & $15(100)$ & $11(100)$ & $23(100)$ & $29(97)$ & $20(70)$ & $19(78)$ & 9.6 & 4.76 \\
\hline Impact: $n(\%)$ & $0(0)$ & $0(0)$ & $0(0)$ & $1(1)$ & $6(30)$ & $4(22)$ & $0.008^{*}$ & 0.09 \\
\hline \multicolumn{9}{|c|}{ 13.Felt life in general less satisfactory } \\
\hline No impact: $n(\%)$ & $14(93)$ & $9(82)$ & $18(78)$ & $25(83)$ & $16(62)$ & $13(56)$ & 5.3 & 5.2 \\
\hline Impact: $n(\%)$ & $1(7)$ & $2(8)$ & $5(22)$ & $5(17)$ & $10(38)$ & $10(44)$ & 0.07 & 0.07 \\
\hline \multicolumn{9}{|c|}{ 14. Have been unable to function } \\
\hline No impact: $n(\%)$ & $12(80)$ & $11(100)$ & $17(74)$ & $30(100)$ & $6(23)$ & $18(78)$ & 17.7 & 9.6 \\
\hline Impact: $n(\%)$ & $3(20)$ & $0(0)$ & $6(26)$ & $0(0)$ & $20(77)$ & $5(22)$ & $0.001^{*}$ & $0.008^{*}$ \\
\hline
\end{tabular}

\begin{tabular}{lc} 
Table 4: Treatment need grade for IOTN-AC record \\
\hline IOTN-AC & Frequency (n) \% \\
\hline No/Slight Need & $50.8(64)$ \\
Borderline/Moderate need & $34.9(44)$ \\
Need to Treatment & $14.3(18)$ \\
Total & $100(126)$ \\
\hline
\end{tabular}

severity in both males and females. This result is in accordance with the findings of cross-sectional studies by English JD et al. and Magalhães IB et al. They stated that malocclusion can affect the diet and mastication of patients. ${ }^{[31,32]}$ On the other hand, Daniels and Richmond reported that physical aspects 
of malocclusion such as decreased masticatory force and unsatisfactory diet affect the QoL to a lesser extent compared to esthetic consequences. ${ }^{[33]}$

In our study, being self-conscious and feeling embarrassed in both males and females had a direct correlation with malocclusion severity. Klages et al. discussed that young adults with more severe malocclusion acquired higher scores in self-consciousness domain, which means increased feeling of embarrassment and self-consciousness. ${ }^{[34]}$ The results of this study are in agreement with those of Hassan and Amin who reported that embarrassment and self-consciousness were significantly correlated with orthodontic treatment need. ${ }^{[4]}$ Our results are similar to those of Hassan and Amin and Silvola et al. which demonstrated that by an increase in malocclusion severity, most patients felt more embarrassed in public and had higher orthodontic treatment need. ${ }^{[4,5]}$

Helm et al. reported that self-consciousness and embarrassment due to severe malocclusion were not limited to adolescents and were seen in adults as well. ${ }^{[35]}$ However, studies by Lazaridou-Terzoudi et al. and DiBiase and Sandler found no significant association between malocclusion and self-consciousness or embarrassment. ${ }^{[36,37]}$

Some retrospective, cross-sectional studies reported that patients with more severe malocclusion and higher orthodontic treatment need suffered more of social deprivation and rejection than those with mild malocclusion; the consequence of which would be isolation and depression of patients because appearance is an important and influential factor in social activities and interpersonal relations. ${ }^{[4,36,38]}$ In the current study, we observed higher frequency of feeling tense, embarrassed, and irritable in patients with high orthodontic treatment need compared to those with mild or borderline malocclusion.

The results of this study indicated a significant correlation between orthodontic treatment need in males and females and their life satisfaction. Kiyak et al. concluded that a direct correlation existed between the orthodontic treatment need and life satisfaction and explained that this is because orthodontic patients are not psychologically satisfied with their facial and dental appearance. This decreases their self-confidence and creates a sense of negativity in these patients. ${ }^{[39]}$ De Baets, Agou, Oliveira, and O'Brien also confirmed the above-mentioned findings. ${ }^{[26,40-42]}$
The effects of malocclusion on physical and mental domains of QoL have been confirmed. However, according to Heravi et al., the extent of these effects, especially on the Iranian population, has yet to be clearly elucidated. ${ }^{[12]}$ According to Hassan and Amin and Heravi et al., one reason for this finding can be absence of a systematic method for assessment of this topic. ${ }^{[4,12]}$ Thus, our study aimed to assess the OHRQoL in orthodontic patients. The validity of OHIP-14 questionnaire used in this study was first confirmed for use in orthodontic patients; this questionnaire has been used in some previous studies to assess the effect of malocclusion on the QoL. ${ }^{[4,10]}$ The validity and reliability of this questionnaire have been previously confirmed in cross-sectional and longitudinal studies. ${ }^{[8,43]}$ In our study, children were not included since they may not adequately perceive the questions. Adolescents were not included due to physical and mental changes that occur during the puberty (affecting their QoL). According to Hassan and Amin, changes during the puberty make it difficult to assess the factors affecting the QoL and orthodontic treatment need. [4] Thus, our study was conducted on young adults, since they can perceive the questions and have passed the pubertal period.

\section{CONCLUSIONS}

The application of IOTN-DHC and IOTN-AC has its own shortcomings. Although these tools are really reliable and valid, they are not very sensitive for some slight dental discrepancies. Slight occlusal interferences may greatly affect the appearance of patients and cause concerns in some patients. To increase the accuracy in recording occlusal relations, adjunct tools can be used in future studies. In conclusion, the current study results indicated the significant effects of malocclusion severity on OHRQoL of young adults and showed the importance of personal assessment of patient needs and treatment needs. Clinicians should pay more attention to the mental and physical effects of malocclusion on the QoL of patients to better prioritize the therapeutic needs of their patients and their participation in treatment.

\section{Financial support and sponsorship Nil.}

\section{Conflicts of interest}

There are no conflicts of interest. 


\section{REFERENCES}

1. Dimberg L, Arnrup K, Bondemark L. The impact of malocclusion on the quality of life among children and adolescents: A systematic review of quantitative studies. Eur J Orthod 2015;37:238-47.

2. Brondani MA, MacEntee MI. Thirty years of portraying oral health through models: What have we accomplished in oral health-related quality of life research? Qual Life Res 2014;23:1087-96.

3. Choi SH, Kim BI, Cha JY, Hwang CJ. Impact of malocclusion and common oral diseases on oral health-related quality of life in young adults. Am J Orthod Dentofacial Orthop 2015;147:587-95.

4. Hassan AH, Amin HE. Association of orthodontic treatment needs and oral health-related quality of life in young adults. Am J Orthod Dentofac Orthop 2010;137:42-7.

5. Silvola AS, Rusanen J, Tolvanen M, Pirttiniemi P, Lahti S. Occlusal characteristics and quality of life before and after treatment of severe malocclusion. Eur J Orthod 2012;34:704-9.

6. Borzabadi-Farahani A, Borzabadi-Farahani A, Eslamipour F. Malocclusion and occlusal traits in an urban Iranian population. An epidemiological study of 11- to 14-year-old children. Eur J Orthod 2009;31:477-84.

7. Rusanen J, Lahti S, Tolvanen M, Pirttiniemi P. Quality of life in patients with severe malocclusion before treatment. Eur J Orthod 2010;32:43-8.

8. Liu Z, McGrath C, Hägg U. The impact of malocclusion/orthodontic treatment need on the quality of life. A systematic review. Angle Orthod 2009;79:585-91.

9. Masood M, Masood Y, Saub R, Newton JT. Need of minimal important difference for oral health-related quality of life measures. J Public Health Dent 2014;74:13-20.

10. Masood Y, Masood M, Zainul NN, Araby NB, Hussain SF, Newton T, et al. Impact of malocclusion on oral health related quality of life in young people. Health Qual Life Outcomes 2013;11:25.

11. Andiappan M, Gao W, Bernabé E, Kandala NB, Donaldson AN. Malocclusion, orthodontic treatment, and the oral health impact profile (OHIP-14): Systematic review and meta-analysis. Angle Orthod 2015;85:493-500.

12. Heravi F, Farzanegan F, Tabatabaee M, Sadeghi M. Do malocclusions affect the oral health-related quality of life? Oral Health Prev Dent 2011;9:229-33

13. Feu D, de Oliveira BH, de Oliveira Almeida MA, Kiyak HA, Miguel JA. Oral health-related quality of life and orthodontic treatment seeking. Am J Orthod Dentofac Orthop 2010;138:152-9.

14. Taylor KR, Kiyak A, Huang GJ, Greenlee GM, Jolley CJ, King GJ. Effects of malocclusion and its treatment on the quality of life of adolescents. Am J Orthod Dentofac Orthop 2009;136:382-92.

15. De Oliveira C, Sheiham A, Tsakos G, O'Brien K. Oral health-related quality of life and the IOTN index as predictors of children's perceived needs and acceptance for orthodontic treatment. Br Dent J 2008;204:E12.

16. Pugaca J, Urtane I, Pirttiniemi P, Rogovska I. Validation of a Latvian and a Russian version of the oral health impact profile for use among adults. Stomatologija 2014;16:83-6.

17. Vikram M, Singh VP. Translation and validation of the Nepalese version of oral health impact profile (OHIP-14) questionnaire. Oral Biol Dent 2014;2:3.

18. Santucci D, Camilleri L, Kobayashi Y, Attard N. Development of a Maltese version of oral health-associated questionnaires: OHIP-14, GOHAI, and the denture satisfaction questionnaire. Int J Prosthodont 2014;27:44-9.

19. Asgari I, Ahmady AE, Broder H, Eslamipour F, Wilson-Genderson M. Assessing the oral health-related quality of life in Iranian adolescents: Validity of the Persian version of the child oral health impact profile (COHIP). Oral Health Prev Dent 2013;11:147-54.

20. Navabi N, Nakhaee N, Mirzadeh A. Validation of a Persian version of the oral health impact profile (OHIP-14). Iran J Public Health 2010;39:135-9.

21. Sischo L, Broder H. Oral health-related quality of life what, why, how, and future implications. J Dent Res 2011;90:1264-70.

22. Dhingra $\mathrm{K}$, Vandana KL. Indices for measuring periodontitis: A literature review. Int Dent J 2011;61:76-84.

23. Slade GD. Derivation and validation of a short-form oral health impact profile. Community Dent Oral Epidemiol 1997;25:284-90.

24. Hedayati Z, Fattahi H, Jahromi S. The use of index of orthodontic treatment need in an Iranian population. J Indian Soc Pedod Prev Dent 2007;25:10.

25. Bernabé E, de Oliveira CM, Sheiham A. Condition-specific sociodental impacts attributed to different anterior occlusal traits in Brazilian adolescents. Eur J Oral Sci 2007;115:473-8.

26. de Oliveira CM, Sheiham A. Orthodontic treatment and its impact on oral health-related quality of life in Brazilian adolescents. J Orthod 2004;31:20-7.

27. Lee AS, Whitehill TL, Ciocca V, Samman N. Acoustic and perceptual analysis of the sibilant sound/s/ before and after orthognathic surgery. J Oral Maxillofac Surg 2002;60:364-72.

28. WrightEF, NorthSL. Management and treatment of temporomandibular disorders: A clinical perspective. Journal of Manual \& Manipulative Therapy 2009;17:247-54.

29. Koroluk LD, Tulloch JF, Phillips C. Incisor trauma and early treatment for class II division 1 malocclusion. Am J Orthod Dentofacial Orthop 2003;123:117-25.

30. Shulman JD, Peterson J. The association between incisor trauma and occlusal characteristics in individuals 8-50 years of age. Dent Traumatol 2004;20:67-74.

31. English JD, Buschang P, Throckmorton G. Does malocclusion affect masticatory performance? Angle Orthod 2002;72:21-7.

32. Magalhães IB, Pereira LJ, Marques LS, Gameiro GH. The influence of malocclusion on masticatory performance. A systematic review. Angle Orthod 2010;80:981-7.

33. ENG F. The development of the index of complexity, outcome and need (ICON). Journal of Orthodontics 2000;27:149-62.

34. Klages U, Bruckner A, Zentner A. Dental aesthetics, self-awareness, and oral health-related quality of life in young adults. Eur J Orthod 2004;26:507-14.

35. Helm S, Kreiborg S, Solow B. Psychosocial implications of malocclusion: A 15-year follow-up study in 30-year-old Danes. Am J Orthod 1985;87:110-8.

36. Lazaridou-Terzoudi T, Kiyak HA, Moore R, Athanasiou AE, Melsen B. Long-term assessment of psychologic outcomes of orthognathic surgery. J Oral Maxillofac Surg 2003;61:545-52.

37. DiBiase AT, Sandler PJ. Malocclusion, orthodontics and bullying. Dent Update 2001;28:464-6.

38. Hawker DS, Boulton MJ. Twenty years' research on peer victimization and psychosocial maladjustment: A meta-analytic review of cross-sectional studies. J Child Psychol Psychiatry 2000;41:441-55.

39. Kiyak HA, Hohl T, West RA, McNeill RW. Psychologic changes in orthognathic surgery patients: A 24-month follow up. J Oral Maxillofac Surg 1984;42:506-12.

40. Agou S, Locker D, Muirhead V, Tompson B, Streiner DL. Does psychological well-being influence oral-health-related quality of life reports in children receiving orthodontic treatment? Am J Orthod Dentofacial Orthop 2011;139:369-77.

41. De Baets E, Lambrechts H, Lemiere J, Diya L, Willems G. Impact of self-esteem on the relationship between orthodontic treatment need and oral health-related quality of life in 11- to 16-year-old children. Eur J Orthod 2012;34:731-7.

42. O'Brien C, Benson PE, Marshman Z. Evaluation of a quality of life measure for children with malocclusion. J Orthod 2007;34:185-93.

43. Zhang M, McGrath C, Hägg U. The impact of malocclusion and its treatment on quality of life: A literature review. Int J Paediatr Dent 2006;16:381-7. 